\title{
Domestic pigeons (Columba livia) discriminate between photographs of individual pigeons
}

\author{
TAMO NAKAMURA, DAVID B. CROFT, and R. FREDERICK WESTBROOK \\ University of New South Wales, Sydney, New South Wales, Australia
}

\begin{abstract}
In two experiments, we examined the discrimination of photographs of individual pigeons by pigeons, using go/no-go discrimination procedures. In Experiments 1A and 1B, the pigeons were trained to discriminate 4 photographs of one pigeon from those of a number of pigeons. The subjects learned the discrimination, but their discriminative behavior did not transfer to new photographs taken from novel perspectives. When the pigeons were trained to discriminate between 20 photographs of five pigeons taken from four perspectives as the $\mathrm{S}+$ and 20 photographs of five different pigeons as the $\mathrm{S}-$, the subjects learned the discrimination, and this discriminative behavior partially transferred to new photographs taken from novel perspectives (Experiments 2A-2C). The results suggest that pigeons are able to discriminate among conspecific individuals, using stationary visual cues. This strengthens the assumption in evolutionary theory that animals can discriminate among individuals and encourages further investigation as to how this ability is used in various behaviors of animals.
\end{abstract}

In a classic experiment, Herrnstein and Loveland(1964) reported that pigeons sorted photographs into two categories: those that contained people and those that did not. This was accomplished with a differential conditioning procedure in which pecks at photographs with people were periodically rewarded with access to grain, whereas there were no such consequences when people were absent from the photographs. The birds mastered this discrimination and generalized to photographs that had never previously been shown.

Since then, psychologists have demonstrated that pigeons are able to sort photographs distinguished according to whether they do or do not contain exemplars of trees (Herrnstein, Loveland, \& Cable, 1976), chairs, cars, humans, and flowers (Bhatt, Wasserman, Reynolds, \& Knauss, 1988), birds and other animals (Roberts \& Mazmanian, 1988), human faces (Jitsumori \& Yoshihara, 1997; Troje, Huber, Loidolt, Aust, \& Fieder, 1999), color slides of paintings by Monet and Picasso (Watanabe, Sakamoto, \& Wakita, 1995), and the presence and absence of a pigeon (Poole \& Lander, 1971).

These demonstrations suggest that birds might also sort photographs that are distinguished according to whether

This paper is based on part of a doctoral dissertation by T.N. written while she was funded by an Australian Postgraduate Research Award. We thank Mark A. Elgar for his input into the formulation of the experiments and Anthony A. Wright, Peter J. Urcuioli, and anonymous reviewers for helpful comments on an earlier draft of this manuscript. The studies were approved by the Animal Care and Ethics Committee of the University of New South Wales (ACE/CUART 88/58; ACE 92/72). Correspondence concerning this article should be addressed to T. Nakamura, Department of Neurobiology and Anatomy, University of Texas Health Science Center at Houston, P. O. Box 20708, Houston, TX 77225-0708 (e-mail: tamo. nakamura@uth.tmc.edu); or to R. F. Westbrook, School of Psychology, University of New South Wales, Sydney, NSW 2052 Australia (e-mail: f.westbrook@unsw.edu.au.) they contain one bird versus another. However, several studies in which this suggestion has been investigated have been unable to clearly show that birds can sort such photographs on this basis and transfer this discriminative behavior to new photographs (Bradshaw \& Dawkins, 1993; Ryan \& Lea, 1994; Watanabe \& Ito, 1991) or have claimed that any such sorting and transfer depend on prior training involving moving video images (Jitsumori, Natori, \& Okuyama, 1999). Specifically, Jitsumori and her colleagues reported that pigeons learned to discriminate between moving video images of two individual pigeons and that this discriminative behavior transferred to moving video images of the same individual pigeons, suggesting that motion is critical for discrimination by pigeons between two-dimensional stimuli of individual pigeons.

In the present study, we investigated whether motion is critical in the discrimination of individual pigeons, as was suggested by Jitsumori et al. (1999), by using photographs as stimuli. We found that domestic pigeons are able to discriminate between photographs of pigeons and photographs of different pigeons without motion cues (Experiments 1A$1 \mathrm{~B}$ and $2 \mathrm{~A}-2 \mathrm{C})$. We then explored whether the pigeons based their discrimination on memorizing each of the training exemplars or on the categories defined by the identity of individual stimulus pigeons belonging to the classes. This was done by looking at the transfer of the discriminative behavior to new photographs after discrimination among photographs of individual pigeons had been learned. We conducted the test session under extinction, to make the interpretation of the results clear.

\section{EXPERIMENT 1A}

Pigeons were trained to discriminate photographs of themselves from photographs of other pigeons, using stationary 
cues, to investigate whether they are able to discriminate among more than two pigeons. The ability to discriminate one pigeon from other pigeons is useful in choosing mates, maintaining pair bonds, and observing the foraging behavior of an individual. Experiment $1 \mathrm{~A}$ extended the design of previous research (Jitsumori et al., 1999; Ryan \& Lea, 1994; Watanabe \& Ito, 1991) in which pigeons had been trained to discriminate between photographs (or video images) of two individual pigeons.

\section{Method}

\section{Subjects}

Five male and 3 female domestic pigeons (Columba livia), which had served as subjects in an experiment requiring discrimination between photographs of male and female pigeons, were used. The 5 male pigeons consisted of 1 blue barred, 1 red T-pattern, 1 blue checkered, 1 dark blue checkered, and 1 black checkered pigeon; the 3 female pigeons consisted of 1 blue barred and 2 blue checkered pigeons. The photographs used in their previous experiments were not used in any of the experiments reported here. The age of the pigeons ranged from 1 to 10 years, and the pigeons were purchased from a local breeder. Their free-feeding weights ranged from 298 to $445 \mathrm{~g}$. They were maintained at approximately $80 \%$ of their free-feeding weights throughout the experiment. The birds were housed individually in cages $(30 \times 30 \times 30 \mathrm{~cm}[\mathrm{w} \times 1 \times \mathrm{h}])$. The subjects were placed in the same room and, therefore, had visual, auditory, and olfactory contact with other pigeons. Water and grit were available ad lib in their home cages.

\section{Apparatus}

The subjects were trained in a standard Coulbourn Instruments operant chamber $(24 \times 30 \times 29 \mathrm{~cm}[\mathrm{w} \times 1 \times \mathrm{h}])$. The front wall contained a $7.0 \times 6.1 \mathrm{~cm}(\mathrm{w} \times \mathrm{h})$ opaque Perspex screen. The top edge of the screen was $9.5 \mathrm{~cm}$ below the ceiling and was centered on the front wall. A $5.1 \times 5.7 \mathrm{~cm}(\mathrm{w} \times \mathrm{h})$ opening, through which the pigeons had access to a grain feeder, was centered on the front wall. The top edge of this opening was $4.1 \mathrm{~cm}$ below the bottom edge of the screen. The chamber was located in a small room. The room temperature was kept between $22^{\circ} \mathrm{C}$ and $26^{\circ} \mathrm{C}$ with an air conditioning unit, which provided a constant noise that served to attenuate extraneous sounds.

Thirty-five-millimeter slides were projected onto the back of the screen by a Kodak Carousel S-AV 2050 Projector $(f=60 \mathrm{~mm})$. The lens of the projector was located about $15 \mathrm{~cm}$ from the screen, so that the projected image just filled the screen. The screen also served as the response key, and the pigeons responded directly to the screen by pecking. A minimum force of $0.2 \mathrm{~N}$ to the screen was necessary to operate a microswitch, positioned behind the bottom edge of the screen. The force required to operate a microswitch varied, depending on where the pigeons pecked on the screen. The closer they pecked to the microswitch at the bottom of the screen, the smaller the force required. Food was delivered by operating a grain feeder. A light in the magazine was illuminated whenever the grain feeder was raised. An IBM-compatible computer controlled the presentation of stimuli and recorded pecks.

\section{Stimuli}

Five photographs were taken from five different perspectives of the 10 different stimulus pigeons. Eight of these stimulus pigeons were the subjects of the experiment. The photographs were taken approximately from the front $\left(0^{\circ}\right)$, from an angle between the front and the side $\left(45^{\circ}\right)$, from the side $\left(90^{\circ}\right)$, from an angle between the side and the back $\left(135^{\circ}\right)$, and from the back $\left(180^{\circ}\right)$. All the photographs had 1 pigeon in the center of the frame with a uniform green back- ground. All the photographs were taken from the same camera distance. This was done by sitting a stimulus pigeon on a perch in a photographic cage. The perch could be rotated, to take photographs from different views.

\section{Procedure}

Pretraining. The procedure was similar to that described in the section for discrimination training below, except that only the four $\mathrm{S}+$ photographs were used. Black blank slides were used for negative photographs. There was one session.

Discrimination training. The training schedule was similar to that employed by Morgan, Fitch, Holman, and Lea (1976) and Huber and Lenz (1996). The stimulus pool of photographs was divided into two classes. These classes were (1) photographs of the subject itself $(\mathrm{S}+)$ and $(2)$ photographs of seven other pigeons $(\mathrm{S}-)$. Four photographs $\left(45^{\circ}, 90^{\circ}, 135^{\circ}\right.$, and $\left.180^{\circ}\right)$ from each of the eight stimulus pigeons were used. Positive and negative photographs differed across subjects as each of them was reinforced for pecking at its own photographs $(\mathrm{S}+)$. In each daily training session, four photographs from just one of the seven stimulus pigeons were used as the negative stimuli $(\mathrm{S}-)$. The identity of the $\mathrm{S}-$ stimulus pigeon changed across daily sessions in a 7-day cycle.

There were four $\mathrm{S}+$ and four $\mathrm{S}-$ photographs in a session. These were presented in eight rounds, giving a total of 64 trials in a session. The photographs were randomly ordered before each training session. The order of presentation was the same in the odd rounds but was reversed in the even rounds.

In the presence of $\mathrm{S}+$, pecking was reinforced on a variable trial duration schedule from a fixed distribution with a mean duration of $24 \mathrm{sec}$, ranging from 5 to $43 \mathrm{sec}$ in 2 -sec interval steps. The intertrial interval (ITI) was $10 \mathrm{sec}$. The grain feeder opened for $5 \mathrm{sec}$ whenever the subject pecked the screen after the predetermined presentation time had elapsed. The presentation of the slide was prolonged until the subject pecked the screen after this predetermined presentation time had elapsed. In the presence of $\mathrm{S}-$, pecking was not reinforced, and the trial terminated at the end of the predetermined presentation time regardless of whether the screen had been pecked or not.

The subjects received 21 training sessions. A discrimination ratio was calculated by dividing the number of pecks in the presence of $\mathrm{S}+$ by the number of total pecks in the presence of both $\mathrm{S}+$ and $\mathrm{S}-$. After 21 training sessions, all the subjects were discriminating between the two sets of photographs, judging from the responses to the $\mathrm{S}+$ and $\mathrm{S}-$ stimuli across sessions.

Testing. There were four types of stimuli: (1) a photograph of the subject taken from the side $\left(90^{\circ} ; \mathrm{S}+\right)$, (2) seven photographs of seven stimulus pigeons taken from the side $\left(90^{\circ}\right)$ and two new photographs of two novel pigeons taken from the side $\left(90^{\circ} ; \mathrm{S}-\right),(3)$ a new photograph of the subject taken from the front $\left(0^{\circ}\right.$; new $\left.\mathrm{S}+\right)$, and (4) seven new photographs of the seven $\mathrm{S}-$ stimulus pigeons taken from the front $\left(0^{\circ}\right)$ and two new photographs of the two novel $\mathrm{S}-$ pigeons taken from the front $\left(0^{\circ}\right.$; new $\left.\mathrm{S}-\right)$.

The two photographs of itself $(\mathrm{S}+$ and new $\mathrm{S}+$ ) were presented nine times, whereas the rest of the photographs $(\mathrm{S}-$ and new $\mathrm{S}-$ ) were presented once to equate the number of presentations of photographs of the subject (corresponding to the $\mathrm{S}+$ class in training) and photographs of other pigeons (corresponding to the $\mathrm{S}$ - class in training). There were 36 trials in the test session, presented in a single round. Each photograph was presented for $30 \mathrm{sec}$ and was followed by a 30 -sec ITI. The test session was conducted under extinction.

\section{Analyses}

The relative response is defined as the ratio of the number of pecks toward a particular type of stimulus to the total number of pecks toward all four types of stimuli (Watanabe \& Ito, 1991) and, therefore, 
sums to 1.0 across the four types of stimuli $(\mathrm{S}+, \mathrm{S}-$, new $\mathrm{S}+$, and new $\mathrm{S}-$ ). Within-subjects differences in the relative response toward the four types of stimuli used in the tests were analyzed with a set of planned orthogonal contrasts (Hays, 1963) at $\alpha$ (decision-wise) $=$ .05 . This relative response is used in the analyses over the peck rate, since this measure reduces variation between subjects.

\section{Results and Discussion}

The subjects were able to discriminate photographs of themselves from those of other pigeons. The mean ( \pm the standard error of the mean $[S E M]$ ) of the discrimination ratios on the 21 st session was $.87 \pm .04$, ranging from .69 to 1.0 for the 8 subjects. The discrimination ratio for chance performance was .50 . Five out of 8 pigeons were overtrained, in the sense that they had a session with a discrimination ratio of .80 or higher, followed immediately by a session with a discrimination ratio of .75 or higher, prior to the penultimate training session (20th session). These 5 pigeons reached a discrimination ratio of .80 or higher on the 8 th, 9th, 12th, 16th, and 17th training sessions, followed by sessions in which discrimination ratios were .75 or higher.

There were significant differences between the relative responses toward the familiar $\mathrm{S}+$ and the familiar $\mathrm{S}-$ [analysis of variance: $F(1,7)=8.6, p<.05$; Figure 1]. This was in accordance with the results from discrimination training. However, there were no significant differences between the relative responses toward new $\mathrm{S}+$ and new $S-[F(1,7)=1.6, p>.05]$. The pigeons pecked at high rates in the presence of photographs of themselves taken from $90^{\circ}$, which had been used in training, but pecked at low rates in the presence of other photographs, including photographs of themselves taken from $0^{\circ}$, which had not been used in training (i.e., new $\mathrm{S}+$ ).

The pigeons discriminated between photographs of themselves and photographs of seven other pigeons during training but did not maintain this discrimination when tested with photographs taken from an unfamiliar perspective. The lack of transfer in Experiment 1A could have been due to several factors. For instance, the difference between the test and the training stimuli may have been too large for the pigeons to generalize their discriminative behavior toward new photographs. Alternatively, the number of training stimuli used in Experiment 1A may have been too small for the pigeons to form appropriate representations of the two sets of stimulus pigeons or to group the new stimuli into the two relevant classes based on the identity of stimulus pigeons. The training may have simply taught the birds to memorize each of the four $\mathrm{S}+$ stimuli and not to peck at anything else.

\section{EXPERIMENT 1B}

The procedure of Experiment $1 \mathrm{~A}$ was modified to determine whether changes in conditions would result in better transfer of discriminative behavior toward new photographs. The changes were (1) the elimination of the subject's own photographs and (2) the use of the photographs taken from the front $\left(0^{\circ}\right)$ as the training photographs and the photographs taken from the side $\left(90^{\circ}\right)$ as the new photographs on test.

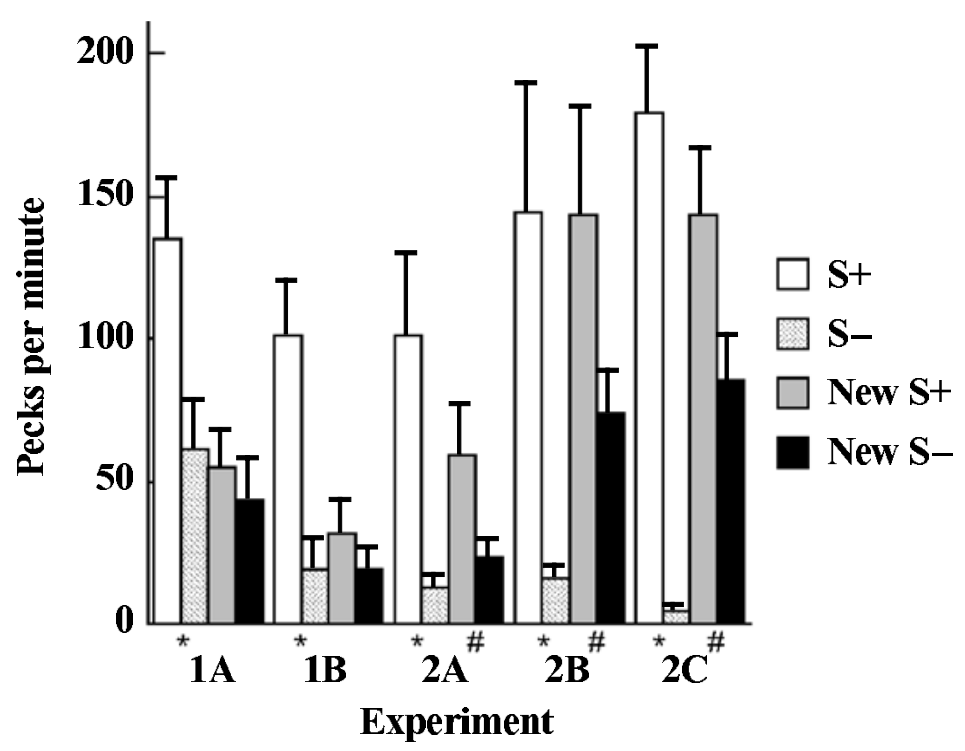

Figure 1. The average (+1 SEM ) pecks per minute toward four ty pes of photographs in the test sessions of Experiment 1A $(N=8)$, Experiment 1B $(N=$ 10), Experiment 2A $(N=10)$, Experiment $2 \mathrm{~B}(N=5)$, and Experiment $2 \mathrm{C}$ $(N=5)$. The asterisk $(*)$ denotes a difference in the relative responses between $S+$ and $S-$ stimuli at $p<.05$. The pound sign (\#) denotes a difference in the relative responses between new $S+$ and new $S-$ stimuli at $p<.05$. 
The subject's own photographs were eliminated in order to exclude the possibility in Experiment $1 \mathrm{~A}$ that the low rates toward new photographs of itself in testing were due to awareness that the photographs were of the subject itself.

Photographs taken from the front may contain information crucial for pigeons to form representations for grouping the photographs into two appropriate classes during training. The social importance of a frontal view is suggested by better recognition of full-face photographs than of profile photographs in humans and by the increased sensitivity of the superior temporal sulcus cells to the full face in macaque monkeys (Bruce, Valentine, \& Baddeley, 1987; Hinde \& Rowell, 1962; Perrett et al., 1985). The inclusion of the frontal view in training might, therefore, have been necessary for the discriminatory behavior to generalize toward new stimuli.

\section{Method}

Subjects

Ten pigeons were used. Eight of these were those used in Experiment 1A. The other 2 male subjects had been used in similar experiments in which they had been trained to discriminate (1) between photographs of pigeons and other species of birds and (2) between line drawings of two different three-dimensional objects. The photographs used in the previous discrimination between pigeon photographs versus other species of birds were not used in any of the experiments reported in this article. These 2 subjects had served as the two stimulus pigeons whose photographs were used as the negative photographs of unfamiliar pigeons in testing in Experiment 1A. Other conditions were the same as those in Experiment 1A.

\section{Apparatus}

Two operant chambers and two Kodak Carousel S-AV 2050 projectors were used so that 2 pigeons could be trained at the same time. The second chamber was similar to the one used in Experiment 1A. This chamber was placed in a box $(59 \times 32 \times 44 \mathrm{~cm}[\mathrm{w} \times 1 \times \mathrm{h}])$ to prevent the subjects from seeing or hearing each other. There was a houselight $(4 \mathrm{~W})$ on the ceiling of the chamber that was located in the box. Other conditions were the same as those in Experiment 1A.

\section{Stimuli}

These were the same as those in Experiment 1A.

\section{Procedure}

Pretraining. All the pigeons received three sessions of training, using their own photographs as positive stimuli and black blank slides as negative stimuli, to reestablish keypecking. Other details were the same as those in the discrimination training in Experiment $1 \mathrm{~A}$.

Discrimination training. The stimulus pool of photographs was divided into two classes: (1) photographs of one individual pigeon and (2) photographs of other pigeons. Both classes excluded photographs of the subject. The photographs taken from $0^{\circ}, 45^{\circ}, 135^{\circ}$, and $180^{\circ}$ were used. Photographs from nine stimulus pigeons were used in training for each of the subjects. For every subject, photographs of one stimulus pigeon (not itself) were assigned as $\mathrm{S}+$ across every session. Positive photographs were again different for each of the 10 subject pigeons. There were photographs from eight stimulus pigeons belonging to the class of other pigeons for each of the subjects $(\mathrm{S}-)$. In each daily training session, photographs from only one pigeon were used as $\mathrm{S}-$. The identity of the pigeon used as the negative stimulus changed across daily sessions in an 8-day cycle. There were 16 training sessions. Other details were the same as those in Experiment 1A.
Testing. The pigeons were tested with a photograph of the $\mathrm{S}+$ pigeon taken from $0^{\circ}$, which had been reinforced in training, a new photograph of the $\mathrm{S}+$ pigeon taken from $90^{\circ}$ (new $\mathrm{S}+$ ), eight photographs of eight $\mathrm{S}-$ pigeons taken from $0^{\circ}$, which had not been reinforced in training $(\mathrm{S}-)$, and eight new photographs of the same eight $\mathrm{S}$ - pigeons taken from $90^{\circ}$ (new $\mathrm{S}-$ ). The two photographs of the $\mathrm{S}+$ pigeons were presented eight times, whereas the rest of the photographs were presented once in order to equate the number of times that the photographs of the one $\mathrm{S}+$ pigeon and the eight other $\mathrm{S}-$ pigeons were presented. There were, therefore, 32 trials in the test session, presented in a single round. To encourage the pigeons to peck more during the stimulus presentation, the ITI was increased to $51 \mathrm{sec}$ (Jenkins \& Sainsbury, 1969). Other details were the same as those in the test phase of Experiment $1 \mathrm{~A}$.

\section{Analyses}

Within-subjects differences in the relative responses toward the four types of stimuli used in test $(\mathrm{S}+, \mathrm{S}-$, new $\mathrm{S}+$, and new $\mathrm{S}-$ ) were analyzed with a set of planned orthogonal contrasts (Hays, $1963)$ at $\alpha$ (decision-wise $)=.05$.

\section{Results and Discussion}

The subjects discriminated between photographs of one $\mathrm{S}+$ pigeon and those of eight other $\mathrm{S}-$ pigeons during discrimination training. The mean $( \pm S E M)$ of discrimination ratios was $.83 \pm .05$, ranging from .57 to .98 on the 16 th session for the 10 subjects. The discrimination ratio for chance performance was .50. Nine out of 10 pigeons were overtrained, as defined in Experiment 1A.

During testing, the pigeons pecked at a high rate toward the $\mathrm{S}+$ photographs but pecked at low rates toward the $\mathrm{S}-$, new $\mathrm{S}+$, and new $\mathrm{S}-$ photographs (Figure 1). There were significant differences between the relative responses toward $\mathrm{S}+$ and $\mathrm{S}-[F(1,9)=25.0, p<.05]$. The pigeons were able to discriminate photographs of the original $\mathrm{S}+$ pigeon from those of eight other $\mathrm{S}-$ pigeons. There were no significant differences between the relative responses toward the two types of new photographs [new $\mathrm{S}+$ and new $\mathrm{S}-; F(1,9)=4.7, p>.05]$. This indicated that the discrimination was based on the photographs used in training. The discriminative behavior did not transfer to photographs taken from a different perspective.

The results of Experiment 1B were in agreement with those in Experiment 1A. In Experiment 1B, the subjects learned to discriminate between photographs of one $\mathrm{S}+$ pigeon and photographs of eight other S - pigeons. A memorization "strategy" would again work well in training and would prohibit transfer. None of these photographs was of the subjects themselves. The lack of transfer in Experiment 1 A was not due to (1) the use of the subjects' own photographs as $\mathrm{S}+,(2)$ the omission of photographstaken from the front $\left(0^{\circ}\right)$ in training, or (3) the new test stimuli's looking different from the training stimuli.

\section{EXPERIMENT 2A}

The pigeons were trained to discriminate between photographs of five pigeons and photographs of five different pigeons. The pigeons were assumed to be able to discriminate among photographs of individual pigeons if they 
were able to discriminate photographs of five pigeons from photographs of a different five pigeons. This is because the two classes could be defined only in terms of the individuals constituting the classes, and not solely by related characteristics, such as plumage colors and patterns of the subject pigeons in the two classes (Monen, Brenner, \& Reynaerts, 1998). The increase in the numbers of stimulus pigeons in the positive and the negative classes also enabled an experimental design that reduced the novelty of the perspective from which the new stimuli were taken on test.

\section{Method}

Subjects

The 10 pigeons from Experiment 1B were used. Holding conditions were the same as those in Experiment 1A.

\section{Apparatus}

The apparatus was the same as that used in Experiment 1B.

\section{Stimuli}

The stimuli were the same as those used in Experiment 1B. The two classes to be discriminated were two different sets of five pigeons. One set included photographs of Stimulus Pigeons A (a blue barred), B (a red T-pattern with white primary remiges), C (a dark blue checkered), D (a blue checkered), and E (a silver barred). The other set included photographs of Stimulus Pigeons F (a blue barred), G (a blue checkered), H (a black checkered), I (a blue checkered), and $\mathbf{J}$ (a silver barred). Pigeons with the same plumage coloration pattern appeared to the experimenters to be similar to each other.

\section{Procedure}

Five pigeons were assigned to Group 1 , and the remaining 5 pigeons were assigned to Group 2. Photographs of Stimulus Pigeons A, B, C, D, and E were used as S+, and those of Stimulus Pigeons F, G, H, I, and J were used as $\mathrm{S}-$ for the 5 subjects in Group 1 (Table 1). Photographs of Stimulus Pigeons F, G, H, I, and J were used as S+, and those of Stimulus Pigeons A, B, C, D, and E were used as Sfor the 5 subjects in Group 2.

Pretraining. All the pigeons received one session of training, using $20 \mathrm{~S}+\mathrm{s}$ and black blank slides as $\mathrm{S}-$ to ensure keypecking. Other details were the same as those described in the Discrimination Training section, below.

Discrimination training. Four views from each stimulus pigeon were used. These differed across stimulus pigeons in the manner shown in Table 1.

There were $20 \mathrm{~S}+\mathrm{s}$ and $20 \mathrm{~S}-\mathrm{s}$. The variable trial duration schedule was changed from Experiments $1 \mathrm{~A}$ and $1 \mathrm{~B}$, to accommodate the difference in the numbers of photographs used in a session. The average duration of each photograph presentation was $28.5 \mathrm{sec}$, ranging from 5 to $62 \mathrm{sec}$ in steps of $3 \mathrm{sec}$. Forty photographs ( 5 stimulus pigeons $\times 4$ views $\times 2$ classes) were presented twice in two rounds, giving 80 trials. The order of photograph presentation was reversed in the second round. All the subjects received 20 training sessions. Other details were the same as those in Experiment 1B.

Testing. One view from each of the five positive stimulus pigeons used in training served as $\mathrm{S}+$. This view differed across the stimulus pigeons and is italicized in Table 1. The view that was not used in training of these stimulus pigeons served as the new positive photographs (new $\mathrm{S}+$ ). Similarly, one view from each of the five negative stimulus pigeons used in training served as $\mathrm{S}-$. This view also differed across the stimulus pigeons and is italicized in Table 1. The view that was not used in training of these negative stimulus pigeons served as the new negative photographs (new $\mathrm{S}-$ ).

Twenty photographs (5 stimulus pigeons $\times 2$ views $\times 2$ classes) were presented three times in three rounds, giving 60 trials in a ses-
Table 1

Reinforcement Contingency for Subjects in Groups 1 and 2 and Perspectives (in Degrees) From Which Photographs Were Taken From Each Stimulus Pigeon Used in Training in Experiment $2 \mathrm{~A}(N=10)$

\begin{tabular}{|c|c|c|c|}
\hline \multicolumn{2}{|c|}{$\mathrm{S}+$} & \multicolumn{2}{|c|}{$\mathrm{S}-$} \\
\hline Stimulus Pigeon & Perspectives & Stimulus Pigeon & Perspectives \\
\hline \multicolumn{4}{|c|}{ Group 1} \\
\hline A & $0,45,90,135$ & $\mathrm{~F}$ & $45,90,135,180$ \\
\hline $\mathrm{B}$ & $0,90,135,180$ & $\mathrm{G}$ & $0,45,135,180$ \\
\hline $\mathrm{C}$ & $0,45,90,180$ & $\mathrm{H}$ & $0,45,90,135$ \\
\hline $\mathrm{D}$ & $45,90,135,180$ & I & $0,90,135,180$ \\
\hline $\mathrm{E}$ & $0,45,135,180$ & $\mathrm{~J}$ & $0,45,90,180$ \\
\hline \multicolumn{4}{|c|}{ Group 2} \\
\hline $\mathrm{F}$ & $0,45,90,135$ & A & $45,90,135,180$ \\
\hline $\mathrm{G}$ & $0,90,135,180$ & B & $0,45,135,180$ \\
\hline $\mathrm{H}$ & $0,45,90,180$ & $\mathrm{C}$ & $0,45,90,135$ \\
\hline I & $45,90,135,180$ & $\mathrm{D}$ & $0,90,135,180$ \\
\hline $\mathrm{J}$ & $0,45,135,180$ & $\mathrm{E}$ & $0,45,90,180$ \\
\hline
\end{tabular}

Note-The italicized perspectives indicate the training photographs used in the test session for each stimulus pigeon according to the reinforcement contingency.

sion. There were the five $S+$ photographs used in training $(S+)$, five new $\mathrm{S}+$ photographs (new $\mathrm{S}+$ ), the five $\mathrm{S}-$ photographs used in training $(S-)$, and five new $S-$ photographs (new $S-$ ). Other details were the same as those in testing in Experiment $1 \mathrm{~B}$.

\section{Results}

\section{Discrimination training}

The mean $( \pm S E M)$ of discrimination ratios on the 20 th training session was $.81 \pm .04$, ranging from .66 to .98 for the 10 subjects. Examination of the average peck rates on the 20th training session for each stimulus pigeon across subjects and separately for Groups 1 and 2 revealed that the subjects pecked at higher rates for all $\mathrm{S}+$ stimulus pigeons and at lower rates for all $\mathrm{S}-$ stimulus pigeons across perspectives (Table 2). Similarly, the average peck rates for each perspective across subjects, combined for Groups 1 and 2 on the 20th training session, revealed that the subjects pecked at higher rates for all five perspectives in the positive class and pecked at lower rates for all five perspectives in the negative class across stimulus pigeons (Table 3 ). Five of the 10 subjects were overtrained, as defined in Experiment 1A.

\section{Testing}

The results from Groups 1 and 2 were combined. There were significant differences between the relative responses toward $\mathrm{S}+$ and $\mathrm{S}-[F(1,9)=58.3, p<.05]$ and between the relative responses toward new positive (new $\mathrm{S}+$ ) and new negative (new $\mathrm{S}-$ ) exemplars $[F(1,9)=15.4, p<.05$; Figure 1]. The means ( $\pm S E M s$ ) of discrimination ratios were $.88 \pm .037$ and $.65 \pm .039$ for the training and the new stimuli, respectively. The pigeons were able to discriminate between the two different sets of photographs of five pigeons. The discriminative behavior partially transferred to the photographs taken from new perspectives. There was a significant difference between the relative re- 
sponses toward training $(\mathrm{S}+$ and $\mathrm{S}-$ ) and new (new $\mathrm{S}+$ and new $\mathrm{S}-$ ) photographs $[F(1,9)=11.5, p<.05]$. This indicated that the pigeons discriminated between the photographs used in training and the new photographs used in the test session.

\section{Discussion}

The results from Experiment 2A showed that pigeons learned to discriminate between two sets of photographs, each taken from five different pigeons. These results are in accordance with those obtained in the studies by Watanabe (1992) and Bradshaw and Dawkins (1993), in which pigeons and hens were able to learn the discrimination between photographs of two pigeons or hens. These results are different from those obtained in the study by Ryan and Lea (1994), in which 5 out of 6 pigeons did not learn the discrimination between photographs of two pigeons. The similarity among the stimulus pigeons used in the study by Ryan and Lea may have been greater than the similarity among the stimulus pigeons used in Experiment $2 \mathrm{~A}$.

In Experiment 2A, the discriminative behavior partially transferred to new photographs. This partial transfer appears to be better than the partial transfer obtained by the single pigeon that learned the discrimination in the study by Ryan and Lea (1994). The results were contrary to the findings of Bradshaw and Dawkins (1993) and Watanabe and Ito (1991), in which pigeons were trained with photographs of two different-looking pigeons. There are at least four reasons for lack of transfer in the experiment reported by Bradshaw and Dawkins versus the partial transfer found here: (1) A larger number of stimuli were used in Experiment $2 \mathrm{~A}(20 \mathrm{~S}+\mathrm{s}$ and $20 \mathrm{~S}-\mathrm{s})$, as compared with the experiment in Bradshaw and Dawkins (10 S+s and $10 \mathrm{~S}-\mathrm{s})$; (2) the similarity between training and testing stimuli may have been higher in Experiment 2A than in the experiment in Bradshaw and Dawkins; (3) the subjects were familiar with the perspective of the testing stimuli in Experiment 2A, but not in the experiment in Bradshaw and Dawkins; and (4) the subjects in Experiment $2 \mathrm{~A}$ discriminated between photographs better than did those in the experiment in Bradshaw and Dawkins at the end of the training phase.

The discrimination and partial transfer in Experiment 2A are assumed to be based on the ability of pigeons to discriminate between photographs of different individuals, since the two classes of different individuals can be defined only by the identity of the stimulus pigeons in each class. Detailed examination of peck responses also showed that the peck responses were controlled by the reinforcement contingency, and the peck responses to photographs of different stimulus pigeons and different perspectives were similar within each class. In other words, the pigeons did not show a low response rate to photographs of a particular pigeon or to photographs taken from a particular perspective in the positive class. They also did not show a high response rate to photographs of a particular pigeon or to photographs taken from a particular perspective in the negative class.
The degree of overtraining did not differ substantially among Experiments 1A, 1B, and 2A. The lack of transfer in Experiments $1 \mathrm{~A}$ and $1 \mathrm{~B}$ versus the presence of partial transfer in Experiment 2A are, therefore, likely to be due to (1) the increase in the number of training exemplars, (2) familiarity with the perspectives of the new photographs, and/or (3) repeated testing.

\section{EXPERIMENT 2B}

Experiment 2B was conducted to find out whether the partial transfer of the learned discriminative behaviors in Experiment 2A was due simply to repeated training and testing ("practice") with the same photographs as those in Experiments 1A and 1B. Consequently, we repeated the procedure of Experiment $2 \mathrm{~A}$ with naive subjects. The subjects were also trained to a discrimination criterion to eliminate the effect of overtraining.

\section{Method \\ Subjects, Apparatus, and Stimuli}

One female and 4 male experimentally naive pigeons were used. The age of the pigeons ranged from 8 to 14 months. Their freefeeding weights ranged from 204 to $314 \mathrm{~g}$. Holding conditions were the same as those in Experiment 1A. The apparatuses were the same as those in Experiment 1B, as were the stimuli. The two classes to be discriminated were the same sets of five pigeons as in Experiment 2A.

\section{Procedure}

All the pigeons were trained in the same manner as those in Group 2 in Experiment 2A (Table 1).

Pretraining. The birds were first trained to eat from the feeder. With an autoshaping procedure (P. L. Brown \& Jenkins, 1968), they were trained to peck the key when a photograph was back-projected onto the screen. Only one $\mathrm{S}+$ photograph was used. The pigeons were then trained on a fixed-ratio (FR) schedule, which was progressively raised from FR 1 to FR 20.

Discrimination training. The average duration of each photograph presentation was $32 \mathrm{sec}$, ranging from 5 to $59 \mathrm{sec}$ in 18 -secinterval steps. The subjects were trained until they reached a session with a discrimination ratio equal to or higher than .80 , followed by a session with a discrimination ratio equal to or higher than .75 . Other details were the same as those in Experiment 2A.

Testing. There were 20 trials in a round and two rounds, giving 40 trials in a session. The ITI was $10 \mathrm{sec}$. Other details were the same as those in Experiment 2A.

\section{Results and Discussion}

The mean number of sessions required to reach the discrimination criterion and the $S E M$ was $20 \pm 2.1$, ranging from 14 to 27 for the 5 subjects. The mean ( $\pm S E M)$ of discrimination ratios on the last training session was $.84 \pm$ .02 , ranging from .80 to .91 . Examination of the average peck rates on the last training session for each stimulus pigeon and for each perspective revealed that the subjects pecked at higher rates for all $\mathrm{S}+$ stimulus pigeons and at lower rates for all $\mathrm{S}-$ stimulus pigeons across perspectives (Table 2). The subjects also pecked at higher rates for all five perspectives in the positive class and pecked at lower rates for all five perspectives in the negative class across stimulus pigeons (Table 3 ). 
Table 2

Average Peck Rates (Pecks Per Minute) and SEM for Each Stimulus Pigeon in the Positive and the Negative Classes From the Last Training Sessions in Experiments $2 \mathrm{~A}-2 \mathrm{C}(n=5$ or $N=5$ in each group)

\begin{tabular}{|c|c|c|c|c|c|c|c|c|c|c|}
\hline \multirow[b]{2}{*}{ Contingency } & \multirow{2}{*}{$\begin{array}{l}\text { Stimulus } \\
\text { Pigeon }\end{array}$} & \multicolumn{2}{|c|}{$\begin{array}{c}\text { Experiment 2A } \\
\text { (Group 1) } \\
\end{array}$} & \multicolumn{2}{|c|}{ Experiment $2 \mathrm{C}$} & \multirow{2}{*}{$\begin{array}{l}\text { Stimulus } \\
\text { Pigeon }\end{array}$} & \multicolumn{2}{|c|}{$\begin{array}{c}\text { Experiment 2A } \\
\text { (Group 2) } \\
\end{array}$} & \multicolumn{2}{|c|}{ Experiment 2B } \\
\hline & & $M$ & $S E M$ & $M$ & SEM & & $M$ & $S E M$ & $M$ & SEM \\
\hline \multirow[t]{5}{*}{ Positive } & A & 160.7 & 16.05 & 198.9 & 8.69 & $\mathrm{~F}$ & 135.0 & 9.24 & 148.9 & 14.90 \\
\hline & B & 143.4 & 41.44 & 186.0 & 11.09 & G & 117.1 & 20.69 & 153.6 & 17.71 \\
\hline & $\mathrm{C}$ & 141.4 & 39.13 & 209.6 & 11.56 & $\mathrm{H}$ & 129.2 & 31.49 & 182.4 & 18.50 \\
\hline & $\mathrm{D}$ & 150.5 & 40.08 & 213.0 & 8.90 & $\mathrm{I}$ & 144.4 & 37.81 & 168.4 & 17.27 \\
\hline & $\mathrm{E}$ & 142.2 & 38.97 & 221.6 & 13.10 & $\mathbf{J}$ & 125.8 & 35.61 & 156.3 & 17.28 \\
\hline \multirow[t]{5}{*}{ Negative } & $\mathrm{F}$ & 50.1 & 19.68 & 31.7 & 8.68 & A & 32.3 & 13.54 & 33.7 & 7.20 \\
\hline & $\mathrm{G}$ & 6.5 & 5.21 & 19.3 & 6.07 & B & 10.8 & 3.16 & 3.2 & 1.83 \\
\hline & $\mathrm{H}$ & 41.0 & 26.26 & 42.4 & 10.14 & $\mathrm{C}$ & 7.4 & 3.24 & 42.4 & 10.08 \\
\hline & $\mathrm{I}$ & 32.9 & 18.14 & 70.2 & 12.50 & $\mathrm{D}$ & 36.1 & 15.21 & 23.3 & 6.41 \\
\hline & $\mathrm{J}$ & 37.2 & 14.48 & 17.7 & 4.76 & $\mathrm{E}$ & 24.4 & 10.33 & 65.7 & 11.32 \\
\hline
\end{tabular}

There were significant differences between the relative responses toward $\mathrm{S}+$ and $\mathrm{S}-[F(1,4)=235.4, p<.05]$ and between the relative responses toward new positive (new $\mathrm{S}+$ ) and new negative (new $\mathrm{S}-$ ) exemplars $[F(1,4)=$ $34.5, p<.05 ;$ Figure 1]. Discrimination ratios were $.90 \pm$ .016 and $.64 \pm .023$ toward old and new stimuli, respectively. The pigeons were thus able to discriminate between the two different sets of photographs of five pigeons, and this discriminative behavior partially transferred to photographs taken from new perspectives. There was a significant difference between the relative response toward training $(\mathrm{S}+$ and $\mathrm{S}-$ ) and new (new $\mathrm{S}+$ and new $\mathrm{S}-$ ) photographs $[F(1,4)=10.1, p<.05]$, indicating that the pigeons discriminated between the photographs used in training and those used only in the test session.

These results indicate that the partial transfer obtained in Experiment 2A was not simply due to repeated training and testing or to overtraining. Experimentally naive pigeons were able to learn the discrimination between two sets of different individual pigeons, and this discrimination partially transferred to novel photographs. The lack of transfer in Experiments $1 \mathrm{~A}$ and $1 \mathrm{~B}$, and the presence of partial transfer in Experiments $2 \mathrm{~A}$ and $2 \mathrm{~B}$, therefore, are likely to be due to (1) the increase in the number of training exemplars and (2) familiarity with the perspectives of the new photographs. As compared with the subjects in Experiment 2A, the subjects showed a bias to peck at all new photographs in the test session. This may have been due to their lack of a prior experimental history.

\section{EXPERIMENT 2C}

Experiment 2C was conducted with naive pigeons to find out whether the results obtained in Experiment 2B could be replicated when we reversed the assignment of positive and negative categories. The pigeons were also tested with new photographs taken from a perspective never used in training, to find out whether familiarity with the perspectives of the new photographs was necessary for the partial transfer seen in Experiments 2A and 2B.

\section{Method}

\section{Subjects, Apparatus, and Stimuli}

Five experimentally naive pigeons were used. Their free-feeding weights ranged from 192 to 297 g. Holding conditions were the same as those in Experiment 1A. The apparatus, stimuli, and stimulus sets were the same as those in Experiment 2B.

\section{Procedure}

Pretraining. Pretraining was the same as that in Experiment 2B.

Table 3

Average Peck Rates (Pecks Per Minute) and SEM for Each Perspective in the Positive and the Negative Classes From the Last Training Sessions in Experiments 2A-2C

\begin{tabular}{|c|c|c|c|c|c|c|c|}
\hline \multirow[b]{2}{*}{ Contingency } & \multirow[b]{2}{*}{ Perspective $\left({ }^{\circ}\right)$} & \multicolumn{2}{|c|}{$\begin{array}{c}\text { Experiment 2A } \\
\text { (Groups } 1 \text { and } 2, \\
\quad N=10)\end{array}$} & \multicolumn{2}{|c|}{$\begin{array}{c}\text { Experiment } 2 \mathrm{~B} \\
(N=5)\end{array}$} & \multicolumn{2}{|c|}{$\begin{array}{c}\text { Experiment } 2 \mathrm{C} \\
(N=5)\end{array}$} \\
\hline & & $M$ & SEM & $M$ & SEM & $M$ & SEM \\
\hline \multirow[t]{5}{*}{ Positive } & 0 & 134.3 & 23.04 & 172.0 & 16.16 & 210.2 & 11.80 \\
\hline & 45 & 152.7 & 25.22 & 180.8 & 17.56 & 208.7 & 8.41 \\
\hline & 90 & 138.1 & 26.13 & 119.8 & 16.63 & & \\
\hline & 135 & 136.6 & 23.72 & 159.5 & 18.31 & 203.2 & 8.33 \\
\hline & 180 & 132.0 & 23.94 & 177.4 & 15.76 & 201.1 & 10.14 \\
\hline \multirow[t]{5}{*}{ Negative } & 0 & 25.1 & 10.42 & 57.5 & 10.40 & 55.9 & 10.51 \\
\hline & 45 & 19.5 & 9.19 & 33.6 & 8.09 & 37.7 & 7.91 \\
\hline & 90 & 46.1 & 14.02 & 37.6 & 10.26 & & \\
\hline & 135 & 23.2 & 6.25 & 14.4 & 4.20 & 20.6 & 4.84 \\
\hline & 180 & 26.4 & 8.54 & 25.0 & 7.62 & 30.8 & 8.43 \\
\hline
\end{tabular}


Discrimination training. Photographs of Stimulus Pigeons A-E were used as $\mathrm{S}+\mathrm{s}$, and those of Stimulus Pigeons $\mathrm{F}-\mathrm{J}$ were used as $\mathrm{S}-\mathrm{s}$. The subjects were trained with photographs taken from just four angles $\left(0^{\circ}, 45^{\circ}, 135^{\circ}\right.$, and $\left.180^{\circ}\right)$ from each stimulus pigeon. Other details were the same as those in Experiment 2B.

Testing. The subjects were tested using the photographs taken from $135^{\circ}$ as the training photographs and those taken from $90^{\circ}$ as the new photographs. Other details were the same as those in Experiment 2B.

\section{Results and Discussion}

The mean number of sessions required to reach the discrimination criterion and $S E M$ was $18.8 \pm 1.7$, ranging from 15 to 24 for the 5 subjects. The mean $( \pm S E M)$ of discrimination ratios on the last training session was $.86 \pm$ .03 , ranging from .80 to .96 . Examination of the average peck rates on the last training session for each stimulus pigeon and for each perspective revealed that the subjects pecked at higher rates for all the $\mathrm{S}+$ stimulus pigeons and at lower rates for all the $\mathrm{S}-$ stimulus pigeons across perspectives (Table 2). The subjects also pecked at higher rates for all five perspectives in the positive class and pecked at lower rates for all five perspectives in the negative class across stimulus pigeons (Table 3 ).

There were significant differences between the relative responses toward $\mathrm{S}+$ and $\mathrm{S}-[F(1,4)=761.0, p<.05]$ and between the relative responses toward new positive (new $\mathrm{S}+$ ) and new negative (new $\mathrm{S}-$ ) exemplars $[F(1,4)=$ 57.0, $p<.05$; Figure 1]. The discrimination ratios and $( \pm S E M)$ were $.96 \pm .019$ and $.63 \pm .018$ for the old and the new stimuli, respectively. The pigeons were able to discriminate between the two different sets of photographs of five pigeons, and again, this discriminative behavior partially transferred to the photographs taken from new perspectives. There was a significant difference between the relative responses toward training $(\mathrm{S}+$ and $\mathrm{S}-$ ) and new (new $\mathrm{S}+$ and new $\mathrm{S}-$ ) photographs $[F(1,4)=323.3$, $p<.05]$. This indicated that the pigeons discriminated between the photographs used in training and the new photographs used in testing.

Again, experimentally naive pigeons were able to learn the discrimination between two sets of different individual pigeons, and this discrimination partially transferred to novel photographs, this time taken from a novel perspective. The lack of transfer in Experiments $1 \mathrm{~A}$ and $1 \mathrm{~B}$ and the presence of partial transfer in Experiments $2 \mathrm{~A}-2 \mathrm{C}$ are, therefore, likely to have been due to the increase in the number of training exemplars. As compared with the subjects in Experiment 2A, these subjects, like those in Experiment $2 \mathrm{~B}$, showed a bias to peck at the new photographs in the test session. This may have been due to the absence of a prior experimental history of the subjects in the latter two experiments.

\section{GENERAL DISCUSSION}

In Experiments $1 \mathrm{~A}$ and $1 \mathrm{~B}$, we trained pigeons to discriminate between photographs of one pigeon and photographs of a number of other pigeons. When the pigeons were trained in this manner, we found that their discriminative behavior did not transfer to new photographs. To facilitate transfer of discriminative behavior to new photographs based on the identity of the stimulus pigeons, we trained the pigeons to discriminate between photographs of five pigeons and those of five different pigeons in Experiment 2A. We did so because Cook, Wright, and Kendrick (1990) had reported that pigeons showed transfer of a discrimination based on line drawings of birds and mammals when trained with a large, but not a small, number of stimuli. When the pigeons were trained in this manner in Experiment 2A, we found that discriminative behavior by the pigeons partially transferred to novel photographs. This is the first demonstration that pigeons can discriminate photographs based on conspecific individuals and can partially transfer their discriminatory behavior to new photographs (cf. Jitsumori et al., 1999; Ryan \& Lea, 1994; Watanabe \& Ito, 1991). In Experiments 1A and $1 \mathrm{~B}$, the positive stimuli repeatedly presented across sessions were highly familiar to the subjects, whereas the negative stimuli were less familiar because they changed across sessions. The familiarity of the stimuli could have been used as a cue by the pigeons in discriminating the stimuli during training. This possible use of familiarity of the stimuli as a discriminative cue was not present in Experiments $2 \mathrm{~A}-2 \mathrm{C}$.

Our results showed that pigeons discriminate among photographs of more than two individual pigeons. This learned discrimination partially transferred to new photographs of the same pigeons when the pigeons were trained with a large number of exemplars (Experiments 2A-2C), but not when they were trained with a small number of exemplars (Experiments 1A and 1B). The partial transfer of the discriminative behavior to new photographs was demonstrated clearly by employing new $\mathrm{S}-$ photographs, in addition to new $\mathrm{S}+$ photographs, and conducting the generalization test under extinction, thus eliminating the possibility of learning during the test itself. Although transfer tests under extinction in general can produce a rapid loss of discrimination, which can make results difficult to interpret, the results obtained from the test carried out under extinction in Experiments $2 \mathrm{~A}-2 \mathrm{C}$ clearly indicated that pigeons were able to discriminate between new photographs of pigeons taken from a different perspective than those used in training. These findings are important, since they suggest that stationary cues contained in photographs can be used for the recognition of individuals in pigeons. Motion is not crucial for this discrimination, as has been suggested by Jitsumori and her colleagues (Jitsumori et al., 1999).

We currently do not know whether animals see a representation of the world in photographs (Cole \& Honig, 1994; D'Eath, 1998; Fagot, 2000). The colors depicted in the photographs are geared to the trichromatic color vision of humans and, for example, do not reproduce ultraviolet light (Cuthill \& Bennett, 1993; Patterson-Kane, Nicol, Foster, \& Temple, 1997). The visual system of pigeons is at least tetrachromatic and is different from human color 
vision (D'Eath, 1998; Delius \& Emmerton, 1979; Donovan, 1978; Steele, 1992). There is some evidence that young children or people from cultures devoid of photographs do not see a representation of the world in photographs (Deregowski, 1989; Slater, Rose, \& Morrison, 1984). Combined with the fact that photographs are geared to the human visual system, which is different from the avian visual system, it is possible that pigeons do not see a representation of the world in photographs without explicit training to do so. Such training was not conducted in the present experiments.

Discrimination of photographs also does not imply that what is being discriminated is based on the content of photographs perceived by humans (Bradshaw \& Dawkins, 1993; Cabe, 1980; Ryan \& Lea, 1994; Watanabe, Lea, \& Dittrich, 1993). Therefore, the partial transfer of discriminative behavior to new photographs in Experiments 2A$2 \mathrm{C}$ does not necessarily indicate that pigeons understand the photographs as representations of conspecifics, because the partial transfer may have been based simply on the perceived similarity of the new photographs to the training photographs (Vaughan, 1988; Vaughan \& Greene, 1984; Vaughan \& Herrnstein, 1987).

Likewise, the representations of the two classes of individual pigeons held by the pigeons in Experiments $2 \mathrm{~A}-$ $2 \mathrm{C}$ and those held by humans might not be isomorphic. Studies by Dittrich, Gilbert, Green, McGregor, and Grewcock (1993) and Green et al. (1999) have suggested that classification of photographs and objects is similar in pigeons and humans. However, what pigeons and monkeys judge to be good representatives of the classes may be different from what humans consider to be good representatives of the classes (D'Amato \& van Sant, 1988; Dittrich, Lea, Barrett, \& Gurr, 1998; Herrnstein \& de Villiers, 1980; Herrnstein et al., 1976; Schrier \& Brady, 1987). In these experiments, except in the study by Dittrich et al. (1998), photographs were actually judged by humans as good or bad representatives. Lubow (1974) and D'Amato and van Sant also reached the conclusion that the representations of photographs held by pigeons and monkeys are different from those held by humans. This difference between pigeons and humans, for example, may be due to the ways in which pigeons and humans divide the stimuli into features in the discrimination of photographs (Torgerson, 1965).

The present findings nevertheless suggest that pigeons do have the ability to discriminate among individual pigeons in the field and that they can do so in the absence of motion cues that previous research has suggested is critical for discrimination of male and female pigeons and between video images of individual pigeons (Burley, 1981; Jitsumori et al., 1999). This conclusion holds even if pigeons do not see representations of pigeons in the photographs. Pigeons are likely to have the ability to discriminate among individuals in the field without motion, auditory, olfactory, or tactile cues, since they have the ability to discriminate between photographs of individuals and a photograph of an object is a diminished stimulus, as compared with the real object (Delius, Emmerton, Hörster, Jäger, \& Ostheim, 2000).

The present demonstration that animals can discriminate between stimuli, using conditioning procedures, and the usefulness of such an ability in the wild suggest that animals actually discriminate among conspecifics in their natural habitat. However, any such discrimination among individual pigeons in their natural habitats is not necessarily based on the cues contained in photographs alone (Shettleworth, 1993). The information about the color of the birds in the photographs in the present experiments may be different, for pigeons, from the information about the color of actual birds in the field because, as was noted previously, colors in photographs are geared to trichromatic color vision. Nevertheless, information about color conveyed by photographs has previously been suggested to be important for pigeons in learning discrimination between photographs of kingfishers $(\mathrm{S}+)$ and of other bird species (S-; Roberts \& Mazmanian, 1988).

Visual cues not contained in photographs, such as threedimensionality and behavior, or cues from other modalities, such as auditory or olfactory cues or interactions of cues (Dawkins, 1996; D’Eath \& Dawkins, 1996; Maier, 1964), may also be used by themselves or together with two-dimensional structural visual cues to discriminate among conspecifics. Although movement cues are not necessary to discriminate among photographs of individual pigeons, pigeons may nonetheless use movement cues for discrimination of individual pigeons in the field. Further experiments will be necessary to find out whether pigeons prefer to use stationary or movement cues for discrimination of individual pigeons.

The present procedure could not determine which subsets of features contained in the photographs were actually used in the discrimination (S. D. Brown \& Dooling, 1992; Candland, 1969; Cole \& Honig, 1994). Various features, such as color, plumage pattern, size, shape, and posture, could have been used.

The finding, from the present experiments, that pigeons can discriminate among conspecific individuals, using stationary visual cues, contributes to our understanding of evolutionary theory and the models of mate choice proposed by Janetos (1980) and Wittenberger (1983). Since we are more confident with the assumption that animals are able to discriminate among individuals, we can now be ready to test such hypotheses as whether animals actually avoid fighting by identifying the encountered individuals, whether animals strategically place themselves in a flock or a group to observe the behavior of experienced animals, and whether animals choose their mates on the basis of the best-of- $n$ tactic. In addition, the findings from the present experiments provide an excellent basis for designing experiments to find out the following: whether pigeons use stationary, motion, or auditory cues for individual discrimination in the field; in which conditions pigeons use stationary cues and in which conditons they use motion cues for visual categorical discrimination of individual pi- 
geons; which subsets of features are used for discrimination of color photographs of individual pigeons (employing principal component analysis and discriminant analysis; Huber, Troje, Loidolt, Aust, \& Grass, 2000; Troje et al., 1999); why there is a species difference between pigeons and chickens in visual categorical discrimination when the same photographs of individual pigeons as stimuli are used (Ryan, 1982; Ryan \& Lea, 1990, 1994); and how categorical discrimination is influenced by the number of training exemplars and the similarity between the training and the novel testing exemplars.

\section{REFERENCES}

Bhatt, R. S., Wasserman, E. A., Reynolds, W. F., Jr., \& Knauss, K. S. (1988). Conceptual behavior in pigeons: Categorization of both familiar and novel examples from four classes of natural and artificial stimuli. Journal of Experimental Psychology: Animal Behavior Processes, 14, 219-234.

Bradshaw, R. H., \& DAwKIns, M. S. (1993). Slides of conspecifics as representatives of real animals in laying hens (Gallus domesticus). Behavioural Processes, 28, 165-172.

Brown, P. L., \& Jenkins, H. M. (1968). Autoshaping of the pigeon's key-peck. Journal of the Experimental Analysis of Behavior, 11, 1-8.

Brown, S. D., \& Dooling, R. J. (1992). Perception of conspecific faces by budgerigars (Melopsittacus undulatus): I. Natural faces. Journal of Comparative Psychology, 106, 203-216.

Bruce, V., Valentine, T., \& Baddeley, A. (1987). The basis of the 3/4 view advantage in face recognition. Applied Cognitive Psychology, $\mathbf{1}$, 109-120.

BURLEY, N. (1981). The evolution of sexual indistinguishability. In R. D. Alexander \& D. W. Tinkle (Eds.), Natural selection and social behavior (pp. 121-137). New York: Chiron.

CABE, P. A. (1980). Picture perception in nonhuman subjects. In M. A Hagen (Ed.), The perception of pictures: Vol. 2. Durer's devices: Beyond the projective model of pictures (Academic Press Series in Cognition and Perception, pp. 305-343). New York: Academic Press.

CANDland, D. K. (1969). Discriminability of facial regions used by the domestic chicken in maintaining the social dominance order. Journal of Comparative \& Physiological Psychology, 69, 281-285.

Cole, P. D., \& Honig, W. K. (1994). Transfer of a discrimination by pigeons (Columba livia) between pictured locations and the represented environments. Journal of Comparative Psychology, 108, 189-198.

Cook, R. G., Wright, A. A., \& Kendrick, D. F. (1990). Visual categorization by pigeons. In M. L. Commons \& R. J. Herrnstein (Eds.) Quantitative analyses of behavior: Vol. 8. Behavioral approaches to pattern recognition and concept formation (pp. 187-214). Hillsdale, NJ: Erlbaum.

Cuthill, I. C., \& Bennett, A. T. D. (1993). Mimicry and the eye of the beholder. Proceedings of the Royal Society of London: Series B, 253, 203-204.

D' Amato, M. R., \& VAN SANT, P. (1988). The person concept in monkeys (Cebus apella). Journal of Experimental Psychology: Animal Behavior Processes, 14, 43-55.

DAWKINS, M. S. (1996). Distance and social recognition in hens: Implications for the use of photographs as social stimuli. Behaviour, 133, 663-680.

D'EATH, R. B. (1998). Can video images imitate real stimuli in animal behaviour experiments? Biological Reviews, 73, 267-292.

D'EATh, R. B., \& DAwkins, M. S. (1996). Laying hens do not discriminate between video images of conspecifics. Animal Behaviour, 52, 903-912.

Delius, J. D., \& EMmerton, J. (1979). Visual performance of pigeons. In A. M. Granda \& J. H. Maxwell (Eds.), Neural mechanisms of behavior in the pigeon (pp. 51-70). New York: Plenum.

Delius, J. D., Emmerton, J., Hörster, W., JÄger, R., \& Ostheim, J. (2000). Picture-object recognition in pigeons. In J. Fagot (Ed.), Picture perception in animals (pp. 1-35). Hove, U.K.: Psychology Press.
Deregowski, J. B. (1989). Real space and represented space: Crosscultural perspectives. Behavioral \& Brain Sciences, 12, 51-119.

Dittrich, W. [H.], Gilbert, F., Green, P., McGregor, P., \& GrewCock, D. (1993). Imperfect mimicry: A pigeon's perspective. Proceedings of the Royal Society of London: Series B, 251, 195-200.

Dittrich, W. H., Lea, S. E. G., Barrett, J., \& Gurr, P. R. (1998). Categorization of natural movements by pigeons: Visual concept discrimination and biological motion. Journal of the Experimental Analysis of Behavior, 70, 281-299.

Donovan, W. J. (1978). Structure and function of the pigeon visual system. Physiological Psychology, 6, 403-437.

Fagot, J. (2000). Picture perception in animals. Hove, U.K.: Psychology Press.

Green, P. R., Gentle, L., Peake, T. M., Scudamore, R. E., McGregor, P. K., Gilbert, F., \& Dittrich, W. H. (1999). Conditioning pigeons to discriminate naturally lit insect specimens. Behavioural Processes, 46, 97-102.

Hays, W. L. (1963). Statistics for psychologists. New York: Holt, Rinehart and Winston.

Herrnstein, R. J., \& DE Villiers, P. A. (1980). Fish as a natural category for people and pigeons. In G. H. Bower (Ed.), The psychology of learning and motivation (Vol. 14, pp. 59-95). New York: Academic Press.

Herrnstein, R. J., \& Loveland, D. H. (1964). Complex visual concept in the pigeon. Science, 146, 549-551.

Herrnstein, R. J., Loveland, D. H., \& Cable, C. (1976). Natural concepts in pigeons. Journal of Experimental Psychology: Animal Behavior Processes, 2, 285-302.

Hinde, R. A., \& Rowell, T. E. (1962). Communication by postures and facial expressions in the rhesus monkey (Macaca mulatta). Proceedings of the Zoological Society of London, 138, 1-21.

Huber, L., \& Lenz, R. (1996). Categorization of prototypical stimulus classes by pigeons. Quarterly Journal of Experimental Psychology, 49B, 111-133.

Huber, L., Troje, N. F., Loidolt, M., Aust, U., \& Grass, D. (2000). Natural categorization through multiple feature learning in pigeons. Quarterly Journal of Experimental Psychology, 53B, 341-357.

Janetos, A. C. (1980). Strategies of female mate choice: A theoretical analysis. Behavioral Ecology \& Sociobiology, 7, 107-112.

Jenkins, H. M., \& SAinsbury, R. S. (1969). The development of stimulus control through differential reinforcement. In N. J. Mackintosh \& W. K. Honig (Eds.), Fundamental issues in associative learning (pp. 123-161). Halifax, NS: Dalhousie University Press.

Jitsumori, M., NATORI, M., \& OKUYAMA, K. (1999). Recognition of moving video images of conspecifics by pigeons: Effects of individuals, static and dynamic motion cues, and movement. Animal Learning \& Behavior, 27, 303-315.

JiTSUMORI, M., \& YoshiHARA, M. (1997). Categorical discrimination of human facial expressions by pigeons: A test of the linear feature model. Quarterly Journal of Experimental Psychology, 50B, 253-267.

LuBow, R. E. (1974). High-order concept formation in the pigeon. Journal of the Experimental Analysis of Behavior, 21, 475-483.

MAIER, R. A. (1964). The role of the dominance-submission ritual in social recognition of hens. Animal Behaviour, 12, 59.

Monen, J., Brenner, E., \& Reynaerts, J. (1998). What does a pigeon see in a Picasso? Journal of the Experimental Analysis of Behavior, 69, 223-226.

Morgan, M. J., Fitch, M. D., Holman, J. G., \& Lea, S. E. G. (1976). Pigeons learn the concept of an 'A.' Perception, 5, 57-66.

Patterson-Kane, E., Nicol, C. J., Foster, T. M., \& Temple, W. (1997). Limited perception of video images by domestic hens. Animal Behaviour, 53, 951-963.

Perrett, D. I., Smith, P. A. J., Potter, D. D., Mistlin, A. J., Head, A. S., Milner, A. D., \& Jeeves, M. A. (1985). Visual cells in the temporal cortex sensitive to face view and gaze direction. Proceedings of the Royal Society of London: Series B, 223, 293-317.

Poole, J., \& LANDER, D. G. (1971). The pigeon's concept of pigeon. Psychonomic Science, 25, 157-158.

Roberts, W. A., \& Mazmanian, D. S. (1988). Concept learning at different levels of abstraction by pigeons, monkeys, and people. Journal of Experimental Psychology: Animal Behavior Processes, 14, 247-260. 
RyAN, C. M. E. (1982). Concept formation and individual recognition in the domestic chicken Gallus gallus. Behaviour Analysis Letters, 2, 213-220.

RyAN, C. M. E., \& LEA, S. E. G. (1990). Pattern recognition, updating, and filial imprinting in domestic chicken Gallus gallus. In M. L. Commons, R. J. Herrnstein, S. M. Kosslyn, \& D. B. Mumford (Eds.), Quantitative analyses of behavior: Vol. 8. Behavioral approaches to pattern recognition and concept formation (pp. 89-110). Hillsdale, NJ: Erlbaum.

RYAN, C. M. E., \& LEA, S. E. G. (1994). Images of conspecifics as categories to be discriminated by pigeons and chickens: Slides, video tapes, stuffed birds and live birds. Behavioural Processes, 33, 155-176.

Schrier, A. M., \& Brady, P. M. (1987). Categorization of natural stimuli by monkeys (Macaca mulatta): Effects of stimulus set size and modification of exemplars. Journal of Experimental Psychology: Animal Behavior Processes, 13, 136-143.

ShetTleworth, S. J. (1993). Where is the comparison in comparative cognition? Alternative research program. Psychological Science, 4 $179-183$.

Slater, A., Rose, D., \& Morrison, V. (1984). Newborn infants' perception of similarities and differences between two- and three-dimensional stimuli. British Journal of Developmental Psychology, 2, 287-294.

SteEle, K. M. (1992). Confusing structure and function. Behavioral \& Brain Sciences, 15, 52-53.

Torgerson, W. S. (1965). Multidimensional scaling of similarity. Psychometrika, 30, 379-393.

Troje, N. F., Huber, L., Loidolt, M., Aust, U., \& Fieder, M. (1999).
Categorical learning in pigeons: The role of texture and shape in complex static stimuli. Vision Research, 39, 353-366.

VAUGHAN, W. (1988). Formation of equivalence sets in pigeons. Journal of Experimental Psychology: Animal Behavior Processes, 14, 36-42.

Vaughan, W., \& Greene, S. L. (1984). Pigeon visual memory capacity. Journal of Experimental Psychology: Animal Behavior Processes, 10, 256-271.

Vaughan, W., \& Herrnstein, R. J. (1987). Choosing among natural stimuli. Journal of the Experimental Analysis of Behavior, 47, 5-16.

WATANABE, S. (1992). Effect of lesions in the ectostriatum and Wulst on species and individual discrimination in pigeons. Behavioural Brain Research, 49, 197-203.

Watanabe, S., \& Ito, Y. (1991). Discrimination of individuals in pigeons. Bird Behaviour, 9, 20-29.

Watanabe, S., Lea, S. E. G., \& Dittrich, W. H. (1993). What can we learn from experiments on pigeon concept discrimination? In H. P. Zeigler \& H.-J. Bischof (Eds.), Vision, brain and behavior in birds (pp. 351-376). Cambridge, MA: MIT Press.

Watanabe, S., Sakamoto, J., \& Wakita, M. (1995). Pigeons' discrimination of paintings by Monet and Picasso. Journal of the Experimental Analysis of Behavior, 63, 165-174.

Wittenberger, J. F. (1983). Tactics of mate choice. In P. Bateson (Ed.), Mate choice (pp. 435-447). Cambridge: Cambridge University Press.

(Manuscript received February 27, 2003;

revision accepted for publication September 9, 2003.) 